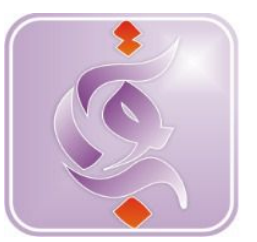

\title{
INDIVIDU BERBAKAT (GIFTEDNESS): TINJAUAN PSIKOLOGI PENDIDIKAN
}

Received: $20^{\text {th }}$ December 2015; Revised: 07th January 2016; Accepted: $27^{\text {th }}$ February 2016

\section{Dewi Fitriana}

IAIN Imam Bonjol Padang

Email : bundadhila@yahoo.co.id

\begin{abstract}
Abstrak: Anak berbakat ini merupakan langkah yang visioner dalam perkembangan pendidikan di Indonesia. Cara pendidik peserta didik, orang tua dan masyarakat dapat saling mendukung dalam program pendidikan. Perlunya wadah belajar bagi anak berbakat pada akhir-akhir ini akan dipandang sebagai langkah maju dalam dunia pendidikan. Keberadaan individual yang beragam perlu mendapat perhatian khusus agar mencapai kemampuan yang optimal.
\end{abstract}

Kata Kunci : Individu berbakat, Psikologi Pendidikan

$\mathrm{S}$ eringkali muncul konsep yang kurang tepat mengenai anak berbakat. Mitos yang dulu sering muncul yaitu individu jenius cenderung mengarah pada kegilaan. Mitos-mitos lain yang sering muncul (Hallahan \& Kauffman, 2006, Parke, 1989) yaitu :

\begin{tabular}{|l|l|}
\hline \multicolumn{1}{|c|}{ Mitos } & \multicolumn{1}{c|}{ Kenyataan } \\
\hline $\begin{array}{l}\text { Individu berbakat adalah sekumpulan } \\
\text { individu yang memiliki kesamaan }\end{array}$ & $\begin{array}{l}\text { Individu berbakat memiliki variasi yang } \\
\text { luas dalam kemampuan, kepribadian, dan } \\
\text { minat }\end{array}$ \\
\hline $\begin{array}{l}\text { Individu berbakat mampu melakukan } \\
\text { segala sesuatu dengan baik }\end{array}$ & $\begin{array}{l}\text { Beberapa individu berbakat memiliki } \\
\text { kemampuan di beberapa bidang, yang lain } \\
\text { di bidang tertentu }\end{array}$ \\
\hline Individu berbakat sempurna & $\begin{array}{l}\text { Individu berbakat memiliki kekuatan dan } \\
\text { keterbatasan }\end{array}$ \\
\hline $\begin{array}{l}\text { Individu berbakat cenderung lemah fisik, } \\
\text { canggung dalam bersosial, minatnya } \\
\text { terbatas dan menunjukkan emosi yang } \\
\text { tidak stabil }\end{array}$ & $\begin{array}{l}\text { Ada banyak variasi pada anak berbakat } \\
\text { dan kebanyakan dari mereka yang } \\
\text { memiliki inteligensi sehat mampu } \\
\text { beradaptasi, mampu bersosial dan mampu } \\
\text { bertanggung jawab secara moral }\end{array}$ \\
\hline
\end{tabular}

\section{Pengertian Keberbakatan}

Berbagai istilah yang diguna-kan untuk memberikan arti pada giftedness, diantaranya :

1. Precocity (kematangan): mengacu pada perkembangan awal yang luar biasa. Anak-anak precocious mengembangkan bakat pada bidang-bidang bahasa, musik, atau matematika pada usia yang sangat muda.

2. Insight: dapat diartikan sebagai keterpisahan secara relevan dengan informasi yang tidak relevan, menemukan hal-hal baru dan menggunakan cara yang tepat mengkombinasikan informasi atau 
menghubungkan informasi yang baru dan lama dengan cara yang kreatif dan baru.

3. Genius: seringkali digunakan se-bagai indikator suatu kemampuan tertentu atau kapasitas tertentu dalam beberapa bidang. Sering-kali digunakan untuk mengin-dikasikan kemampuan inteligensi atau kreativitas yang luar biasa.

4. Creativity: kemampuan untuk mengekspresikan ide yang baru dan bermanfaat, memahami dan mengembangkan hubungan baru dan penting dan mempertanyakan hal-hal yang sebelumnya tak terpikirkan namun penting dan dipertanyakan.

5. Talent: umumnya digunakan untuk mengindikasikan kemam-puan (ability), bakat (aptitude) atau prestasi.

6. Giftedness: mengacu pada kog-nitif (intelektual) yang superior (tidak harus setara dengan jenius), kreativitas dan dorongan dalam mengkombinasikan dan mengatur yang membedakannya dengan rekan sebayanya sehingga memungkinkannya memberikan kontribusi pada nilai-nilai tertentu dalam masyarakat.

Aptitude adalah bakat yang mengacu pada kemampuan khusus yang dimiliki individu sejak lahir yang membutuhkan dukungan dari lingkungan agar dapat berkembang secara optimal. Giftedness adalah keberbakatan mengacu pada kemam-puan-kemampuan unggul di atas kemampuan yag dimiliki individu pada umumnya disertai kreativitas yang cukup serta pengikatan diri terhadap tugas yang cukup pula. Individu yang memilikinya membu-tuhkan layanan pendidikan khusus agar dapat berkembang optimal.

Keduanya dipengaruhi oleh faktor hereditas dan lingkungan, namun keberbakatan mensyaratkan tidak sekedar kemampuan di atas rata-rata (kemampuan intelektual umum dan/atau kemampuan khusus), pengikatan diri terhadap tugas mengacu pada keuletan individu dalam menghadapi rintangan yang menghambat penyelesaian tugas-tugasnya.

Sternberg dalam Hallahan \& Kauffman (2006) menjelaskan teori inteligensi dan menyatakan ada tiga jenis giftedness, antara lain:

1. Analitis: kemampuan untuk memilah masalah, memahami bagian-bagian dari masalah dan bagaimana bagian tersebut saling terkait, dimana kemampuan ini umumnya diukur melalui tes inteligensi konvensional.

2. Sintesis: mencakup insight, intuisi, kreativitas atau kemahiran dalam mengatasi situasi baru, keterampilan yang umumnya diasosiasikan dengan prestasi yang tinggi dalam seni dan sains.

3. Praktikal: mencakup mengaplika-sikan kemampuan analitis dan sintesis dalam menyelesaikan masalah sehari-hari, jenis kete-rampilan ini umumnya merupa-kan karakteristik dari individu yang sukses dalam karir.

Lebih lanjut Munandar, (1992) membedakan pengertian bakat, kemampuan dan prestasi antara lain:

- Bakat (aptitude): pada umumnya diartikan sebagai kemampuan bawaan, sebagai potensi yang masih perlu dikembangkan dan dilatih agar dapat terwujud.

- Kemampuan (performance): daya untuk melakukan suatu tindakan sebagai hasil dari pembawaan dan latihan.

- Prestasi (achievement): perwu-judan dari kemampuan dan bakat.

Pada awal abad 20, individu berbakat identik dengan IQ yang tinggi. Inteligensi dipakai sebagai satu-satunya patokan menentukan berbakat (pendekatan unidimen-sional). Sejak tahun 1960, memberi arti yang lebih luas pada konsep berbakat (pendekatan multidimen-sional). Pemahaman berbakat berubah dari pengertian berdasarkan dimensi tunggal yaitu IQ yang tinggi (Terman, 1925 dalam 
Parke, 1989) mengarah pada kemampuan yang jamak dan inteligensi (Guilford, 1956; Taylor, 1968; Sternberg, 1982, Gardner, 1983 dalam Parke, 1989). Peralihan ini membuka kesempatan untuk memahami individu berbakat serta kebutuhannya di sekolah.

Berikut adalah beberapa definisi mengenai keberbakatan, yaitu:

1. Individu berbakat menurut Dehaan \& Havighurst, 1962:

Individu yang memiliki beberapa kemampuan yang tergolong superior yang memampukan mereka memberikan kontribusi yang luar biasa pada kesejahteraan dan peningkatan kualitas dalam kehidupan bermasyarakat.

2. Diadopsi dari definisi U.S Office of Education, Maryland, 1972 (Coleman, 1985). Anak berbakat adalah individu yang oleh orang-orang profesional diidentifi-kasikan sebagai anak yang mampu mencapai prestasi yang tinggi karena mempunyai kemampuankemampuan yang unggul. Kemampuan-kemam-puan tersebut, baik secara potensial maupun telah nyata meliputi:

- Kemampuan intelektual umum

- Kemampuan akademik khusus

- Kemampuan berpikir kreatifproduktif

- Kemampuan memimpin

- Kemampuan dalam salah satu bidang seni

- Kemampuan psikomotor (seperti olahraga)

3. Three Ring Conception, konsep keberbakatan menurut Renzulli, 1978:

Keberbakatan tersusun atas interaksi dari tiga karakter dasar individu, kemampua umum diatas rata-rata, kreativitas diatas rata-rata, dan pengikatan terhadap tugas (task commitment) yang cukup tinggi.

4. Pengertian pelajar yang tergolong berbakat menurut Winebrenner, 2001:
Dalam konteks belajar di kelas, individu yang berbakat adalah individu yang memiliki kemampuan dalam satu atau lebih bidang pelajaran yang melampaui dua tahun atau lebih tingkatan atau usia yang seharusnya.

\section{Ciri-ciri Khas Anak Berbakat}

1. Menurut Martison, 1974 dalam Munandar, 1992:

- Membaca pada usia muda

- Memiliki perbendaharaan kata yang luas

- Rasa ingin tahu yang kuat

- Inisiatif, mampu bekerja sendiri

- Menunjukkan orisinalitas dalam ungkapan verbal teoritis

- Memberi banyak gagasan

- Luwes dalam berpikir

- Pengamatan tajam

- Berpikir kritis

- Senang mencoba hal-hal baru

- Mempunyai daya abstraksi, konseptualisasi dan sintesis yang tinggi

- Imajinasi yang kuat

- Daya ingat kuat

- Tidak cepat puas dengan prestasinya

2. Menurut Winebrenner, 2001:

- Cepat mempelajari materi baru dan berada pada usia lebih muda dibanding rekan sebayanya.

- Mengingat hal-hal yang dipelajari dalam rentang waktu yang lama, membuat ulasan yang tidak perlu.

- Mampu menghadapi konsepkonsep yang terlalu abstrak dan kompleks untuk individu seusianya.

- Memiliki ketertarikan yang besar terhadap satu atau beberapa topik dan akan menggunakan waktu tersedia untuk mempelajarinya lebih mendalam.

- Tidak terlalu perlu memper-hatikan atau mendengarkan hal-hal yang diajarkan penga-jar, mereka 
mampu mengo-perasionalkan fungsi otak secara simultan dan mampu menyelesaikan lebih dari satu tugas dalam waktu tertentu.

3. Disertasi Reni Hawadi, 2002, lima ciri keberbakatan intelektual yang paling banyak dipilih guru, yaitu:

- Aspek kemampuan belajar:
a. Daya tangkap cepat
b. Mudah memecahkan masalah dengan tepat
c. Kritis
d. Memiliki kecerdasan tinggi
e. Prestasi belajar baik

- Aspek ciri-ciri kreativitas:
a. Kreatif
b. Memiliki inisiatif
c. Berani mengeluarkan dan mempertahankan pendapat
d. Memiliki minat yang luas
e. Aktif sering bertanya dengan tepat

- Aspek ciri-ciri tanggung jawab pada tugas:
a. Tekun
b. Memiliki tanggung jawab
c. Tidak cepat puas
d. Rajin
e. Disiplin dalam belajar

- Aspek ciri-ciri kepribadian:
a. Sopan dalam bersikap
b. Memiliki jiwa kepemim-pinan
c. Mempunyai rasa percaya diri
d. Disegani teman-teman
e. Taat pada peraturan

4. Ciri-ciri keberbakatan berdasar-kan studi literatur Pusat Pengem-bangan Kurikulum dan Sarana Pendidikan Badan Penelitian dan Pengembangan Departemen Pen-didikan dan Kebudayaan (Ma-ngunsong, 1989):

Ciri-ciri keberbakatan untuk tingkat
1. Kelancaran berbahasa

2. Rasa ingin tahu yang bersifat pengetahuan

3. Kemampuan berpikir kritis

4. Kemampuan bekerja mandiri

5. Keuletan

6. Rasa tanggung jawab terhadap tugas

7. Tingkah laku yang terarah pada tujuan

8. Kecermatan dalam mengamati

9. Sering mengungkapkan gagasan atau pendapat baru

10. Senang membuat benda/barang dari bahan yang ada dalam lingkungannya

Ciri-ciri keberbakatan untuk tingkat SMP \& SMA:

1. Kelancaran berbahasa

2. Rasa ingin tahu yang bersifat pengetahuan

3. Kemampuan berpikir logis-kritis

4. Kemampuan bekerja mandiri

5. Keuletan

6. Rasa tanggung jawab pada tugas

7. Tingkah laku yang terarah pada tujuan

8. Kecermatan dalam mengamati

9. Sering mengungkapkan gagasan atau pendapat baru yang konstruktif

10. Mampu memikirkan beberapa macam pemecahan masalah

11. Senang membuat benda/barang dari bahan yang ada dalam lingkungannya

12. Mempunyai minat yang luas

13. Mempunyai daya imajinasi yang tinggi

14. Kemampuan melihat masalah dari beberapa segi.

Karakteristik anak berbakat seringkali mengarah pada beberapa masalah, yang dapat dilihat pada tabel di bawah ini: 


\begin{tabular}{|l|l|}
\hline Karakteristik & Masalah yang mungkin muncul \\
\hline $\begin{array}{l}\text { Kecepatan belajar yang tinggi disertai } \\
\text { kemampuan berpikir abstrak dan } \\
\text { penalaran yang kritis dalam melihat } \\
\text { hubungan antar ide }\end{array}$ & $\begin{array}{l}\text { Menjadi bosan dan frustrasi menghadapi } \\
\text { berbagai repetisi dalam belajar. Terkesan sok } \\
\text { pintar }\end{array}$ \\
\hline Kemampuan bahasa yang luar biasa & $\begin{array}{l}\text { Mendominasi diskusi, kurang memiliki } \\
\text { keterampilan untuk mendengarkan orang lain }\end{array}$ \\
\hline Memiliki tingkat energi yang tinggi & $\begin{array}{l}\text { Tidak membutuhkan banyak tidur, frustrasi } \\
\text { ketika tidak banyak aktivitas yang bisa } \\
\text { dilakukan. Tampak hiperaktif, mudah bosan } \\
\text { tanpa adanya tantangan yang sesuai. }\end{array}$ \\
\hline $\begin{array}{l}\text { Rasa ingin tahu yang besar disertai } \\
\text { dengan minat yang luas }\end{array}$ & $\begin{array}{l}\text { Melakukan terlalu banyak aktivitas, kurang } \\
\text { baik dalam tugas-tugas kelompok, suka } \\
\text { bertanya pada saat yang tidak tepat. }\end{array}$ \\
\hline $\begin{array}{l}\text { Persistensi yang tinggi dalam } \\
\text { menghadapi tugs-tugas yang menarik } \\
\text { baginya. }\end{array}$ & $\begin{array}{l}\text { Mengganggu rutinitas kelas, merasa terkekan } \\
\text { dengan aturan, suka melakukan interupsi, } \\
\text { aturan dianggap sebagai sesuatu yang konyol. }\end{array}$ \\
\hline $\begin{array}{l}\text { Kreatif: banyak ide, luwes dalam } \\
\text { berpikir, ide-idenya orisinil }\end{array}$ & $\begin{array}{l}\text { Sering dianggap aneh, sering dianggap tidak } \\
\text { menghargai figur otoritas, dianggap } \\
\text { pembangkang, tidak patuh. }\end{array}$ \\
\hline $\begin{array}{l}\text { Peka terhadap masalah-masalah moral } \\
\text { dan keadilan serta permasalahan orang } \\
\text { dewasa }\end{array}$ & $\begin{array}{l}\text { Frustrasi menghadapi kondisi lingkungan, } \\
\text { menunjukkan sikap yang sinis terhadap } \\
\text { lingkungan }\end{array}$ \\
\hline Sense of humor yang cukup tinggi & $\begin{array}{l}\text { Menggunakan humor untuk menyerang orang } \\
\text { lain, bingung ketika leluconnya tidak } \\
\text { dipahami orang lain. }\end{array}$ \\
\hline $\begin{array}{l}\text { Lebih suka bergaul dengan anak yang } \\
\text { lebih tua usianya }\end{array}$ & $\begin{array}{l}\text { Mengalami keterasingan ketika bergaul } \\
\text { dengan anak seusianya karena dianggap suka } \\
\text { mencari perhatian, aneh, terlalu pandai, atau } \\
\text { bisa jadi juga ditolak oleh anak yang usianya } \\
\text { lebih tua }\end{array}$ \\
\hline Perfeksionis & $\begin{array}{l}\text { Membuat standar yang tidak realistik bagi } \\
\text { dirinya sendiri maupun orang lain. }\end{array}$ \\
\hline Mandiri & $\begin{array}{l}\text { Kurang suka bekerja dalam kelompok, } \\
\text { kurang kooperatif dalam kerja kelompok. }\end{array}$ \\
\hline $\begin{array}{l}\text { Kemampuan kepemimpinan } \\
\text { kepemahamimpinan memiliki berbagai langkah } \\
\text { kegiatannya. diterapkan dalam }\end{array}$ \\
\hline
\end{tabular}

\section{PEMBAHASAN}

\section{Asal-usul Keberbakatan}

Menurut Plato, keberbakatan tidak diperoleh melalui hereditas. Sedangkan menurut Sir Francis Galton, seorang ilmuwan Inggris, menyatakan bahwa kemampuan intelektual erat kaitannya dengan faktor keturunan dan lingkungan berperan besar memunculkan keberbakatan dalam diri seseorang. Faktor lain yang berperan terhadap inte-ligensi adalah faktor gizi dan neurologik. Studi Terman terhadap individu yang memiliki IQ tinggi menunjukkan keunggulan fisik. Penekanannya adalah bahwa individu tidak diwariskan IQ atau bakat melainkan sekumpulan gen yang bersama dengan pengalaman menen-tukan kapasitas dari inteligensi dan kemampuan lain (Zigler\&Ferber dalam Mangunsong, 1998).

Faktor lingkungan (keluarga, sekolah, teman sebaya, masyarakat) memiliki pengaruh yang besar ter-hadap perkembangan keberba-katan. Faktor keturunan menentukan ren-tang dimana 
indvidu berfungsi, fak-tor lingkungan menentukan penca-paian dari rentang tersebut.

Terman mengadakan studi longitudinal terhadap 1.528 anak berbakat di California yang diikuti perkembangannya dari TK sampai usia pertengahan (lima puluhan). Dari hasil eksplorasi menunjukkan bahwa superioritas intelektual, stabi-litas emosional dan kemampuan penyesuaian diri serta kemajuan hasil belajar setelah mereka dewasa tetap ajeg (Terman \& Oden, 1959 dalam Semiawan, 1997).

\section{Identifikasi dan Intervensi Anak Berbakat}

Pada umumnya ada dua cara untuk mengidentifikasi anak berbakat (Hawadi, 2002):

1. Pengumpulan informasi dengan cara obyektif, melalui tes sehingga data tersedia bersifat kuantitatif. Sumber tes: tes inteligensi, tes prestasi belajar dan nilai prestasi akademik.

2. Pengumpulan informasi yang bersifat subyektif, dalam bentuk daftar (ceklis) perilaku, rekomen-dasi, rujukan berdasarkan peni-laian kemam-puan dan penam-pilan individu.

Langkah asesmen dan alat ukur yang direkomendasikan menurut Farke, 1989:

\begin{tabular}{|c|c|c|}
\hline Langkah asesmen & Tujuan & Alat Ukur \\
\hline Screening & $\begin{array}{l}\text { - Mencari potensi/indikator } \\
\text { dari kemampuan } \\
\text { - Memperoleh data } \\
\text { - Menetapkan kelompok } \\
\text { talent } \\
\text { - Menentukan kebutuhan } \\
\text { program baru }\end{array}$ & $\begin{array}{ll}\text { - } & \text { Nominasi yang } \\
\text { dilakukan oleh guru, } \\
\text { orang tua, individu } \\
\text { - } & \text { Tes IQ kelompok } \\
\text { - } & \text { Tes prestasi } \\
\text { - } & \text { Ranking \& penghargaan }\end{array}$ \\
\hline Identifikasi & $\begin{array}{l}\text { - Mengumpulkan data lebih } \\
\text { mendalam } \\
\text { - Menyesuaikan individu } \\
\text { dengan program } \\
\text { - Menetapkan penempatan }\end{array}$ & $\begin{array}{l}\text { - Kriteria mengacu pada } \\
\text { tes IQ individual } \\
\text { - } \text { Portofolio, audisi }\end{array}$ \\
\hline Perencanaan program & $\begin{array}{l}\text { Menentukan "bagaimana" dan } \\
\text { "apa" dari pengajaran }\end{array}$ & $\begin{array}{l}\text { - } \text { Observasi, } \\
\text { penempatan } \\
- \\
\text { Inventori gaya belajar \& } \\
\text { minat }\end{array}$ \\
\hline Evaluasi & $\begin{array}{l}\text { Mengukur keberhasilan } \\
\text { program dan individu }\end{array}$ & $\begin{array}{ll}- & \text { Hasil tes, survei } \\
\text { - } & \text { Wawancara, observasi }\end{array}$ \\
\hline
\end{tabular}

Program pendidikan bagi indi-vidu berbakat dapat diselenggarakan melalui berbagai cara, yaitu (Semia-wan, 1992):

- Mempercepat waktu belajar (akselerasi), secara menyeluruh atau hanya mata pelajaran tertentu.

- Meluaskan pengalaman dan pengetahuan dengan memperkenal-kan bahan-bahan yang tidak diberikan dalam kurikulum biasa.
- Memberikan kesempatan menda-lami mata pelajaran yang diminati.

- Mengembangkan keterampilan penelitian dan pemecahan masa-lah secara kreatif agar menjadi produsen pengetahuan dan bukan konsumen pengetahuan semata-mata.

Menurut Ward (1980) dalam Mangunsong (1998), individu berba-kat memerlukan pendidikan yang 
berdiferensiasi sesuai dengan minat dan kemampuan intelektualnya. Melalui program khusus individu berbakat akan memperoleh pengaya-an dari materi pelajaran, proses belajar dan produk belajar (Hawadi dkk., 2001). Clendening \& Davies (1983) menyatakan yang dimaksud differentiated adalah isi pelajaran yang menunjuk pada konsep dan proses kognitif tingkat tinggi, strategi instruksional yang akomodatif dengan gaya belajar anak berbakat dan rencana yang memfasilitasi kinerja individu. Kurikulum berdiferensiasi bagi anak berbakat mengacu pada penanjakan kehidupan mental melalui berbagai program yang akan menumbuhkan kreati-vitasnya serta mencakup pengalaman belajar intelektual pada tingkat tinggi (Semiawan, 1997).

Komponen kurikulum berdiferensiasi meliputi antara lain (dalam Hawadi dkk., 2001):

1. Materi pengalaman belajar yang menumbuhkan kreativitas.

2. Terjadi penanjakan dinamis mental dan tindakan kreatif.

3. Berorientasi pada proses, kegiatan aktif dan penerapan tugas serta memberi peluang pada individu memilih kegiatan belajar yang diminatinya.

4. Komponen bersifat teknis, seperti fasilitas, komposisi guru, metode belajar yang variatif.

Matra kurikulum berdiferensiasi (Semiawan, 1992 dalam Hawadi dkk., 2001):

1. Matra Umum: kumpulan kegiatan belajar dasar, kurikulum berdiferensiasi bertitik tolak pada matra ini.

2. Matra didiferensiasikan: berkaitan dengan ciri khas perkembangan anak berbakat, merupakan kurikulum yang dikembangkan secara mendalam sesuai tuntutan kebutuhan peserta didik unggul.

3. Matra Subliminal: terdiri dari pengalaman belajar yang dijabarkan dari lingkungan keluarga dan sekolah.
4. Matra Non Akademis: matra ini dapat digali dari masyarakat, memberikan kesempatan belajar di luar matra kurikulum sekolah.

Terkait dengan istilah diferen-siasi, enrichment dan acceleration merupakan bentuk pengimplementa-siannya. Enrichment (pengayaan): suatu kurikulum yang dimodifikasi melalui beberapa cara pada isi atau dalam strategi mengajar.

Tiga pendekatan pengayaan (dalam Hawadi dkk., 2001):

- Orientasi proses: mengembang-kan proses mental tinggi siswa.

- Orientasi isi: menekankan pada presentasi bidang isi, materi disajikan lebih luas dan mendalam daripada kurikulum reguler.

- Orientasi produk: menekankan pada hasil atau produk dari pengajaran, misalnya laporan, novel, lukisan.

Acceleration (akselerasi): suatu kuri-kulum yang memungkinkan siswa untuk mempercepat penguasaan materi secara tuntas. Akselerasi termasuk:

- Meningkatkan motivasi, kepercayaan, dan pengetahuan

- Mencegah kemalasan mental

- Melengkapi lebih awal latihan profesional

- Mereduksi biaya pendidikan (Van Tassel-Baska, 1986)

\section{Kelompok Siswa Berbakat yang Terabaikan}

Beberapa kondisi dimana siswa tergolong berbakat dan seringkali terabaikan, yaitu (Winebrenner, 2001; Hallahan \& Kauffman, 2006):

a. Siswa tergolong underachiever dengan kemampuan khusus.

b. Siswa berbakat yang berada di taraf sosial ekonomi lemah.

c. Siswa berbakat yang tergolong kelompok minoritas.

d. Siswa berbakat yang memiliki kebutuhan khusus (twice exceptional), yaitu: 
- Siswa berbakat yang disertai ADD/ADHD (Attention Deficit Disorders/Attention Deficit and Hiperactive Disorders)

- Siswa berbakat yang mengalami Asperger's Syndrom

Pada awalnya sindrom Asperger merupakan bentuk tingkat tinggi dari autisme, namun saat ini Asperger sudah dibedakan dengan Autisme. Hal yang paling mendasar membedakan keduanya yaitu pada tingkat kecerdasan. Seseorang yang mengalami sindrom Asperger cenderung tingkat kecerdasannya rata-rata atau diatas rata-rata. Sedangkan pada autisme cenderung kecerdasannya di bawah rata-rata. Karakteristik utama dari sindrom Asperger:

- Mengalami gangguan fungsi sosial: kesulitan dalam berteman, berempati, "membaca" situasi sosial dan berkomunikasi sosial secara nonverbal.

- Minat terbatas dan tingkah laku yang stereotype: sensori yang sensitif, pengulangan yang kompulsif, minat pada satu bidang tertentu dan gerakan tangan berulang-ulang.

- Perkembangan bahasa rata-rata atau diatas rata-rata: penggunaan bahasa norma walaupun beberapa menunjukkan Hyperlexia (senang menggunakan bahasa yang tidak pada umumnya).

- Perkembangan kognitif pada tingkat rata-rata atau diatas rata-rata: taraf inteligensi tergolong rata-rata atau diatas rata-rata.

Perbedaan individu berbakat dengan individu yag mengalami sindrom Asperger:

\begin{tabular}{|l|l|}
\hline Individu berbakat & \multicolumn{2}{|l|}{ Individu mengalami sindrom Asperger } \\
\hline $\begin{array}{l}\text { Dalam bersosialisasi cenderung } \\
\text { terisolasi } \\
\text { - Mandiri dibanding rekan sebaya }\end{array}$ & $\begin{array}{l}\text { Canggung/janggal dalam bersosialisasi } \\
\text { Kurang terampil dalam berelasi dengan } \\
\text { rekan sebaya }\end{array}$ \\
- Fokus tinggi terhadap hal-hal yang \\
$\begin{array}{l}\text { diminati } \\
\text { Kemampuan berbahasa yang baik } \\
\text { - Kognisi kompleks } \\
\text { - Pemahaman yang baik }\end{array}$ & $\bullet \begin{array}{l}\text { Hyperlexia } \\
\text { Rognisinati sederhana }\end{array}$ \\
\hline
\end{tabular}

Perbedaan karakteristik siswa berbakat dengan siswa berbakat yang mengalami sindrom Asperger:

\begin{tabular}{|l|l|l|}
\hline Karakteristik & Asperger Gifted & Asperger Syndrom \\
\hline Rutinitas & Mengikuti rutinitas & $\begin{array}{l}\text { Toleransi rendah terhadap } \\
\text { rutinitas } \\
\text { Kesadaran sosial }\end{array}$ \\
Mampu membedakan dan & Mampu membedakan namun \\
\hline
\end{tabular}




\begin{tabular}{|l|l|l|}
\hline Humor & $\begin{array}{l}\text { mengetahui alasannya } \\
\text { Mampu memberi dan } \\
\text { menerima humor } \\
\text { Keterampilan motorik }\end{array}$ & $\begin{array}{l}\text { tidak mengetahui alasannya } \\
\text { Sulit memahami humor } \\
\text { Insight }\end{array}$ \\
Kerkoordinasi & Tajam insight \\
Mampu berempati & Ceroboh \\
Interaksi sosial & Tahu menjalin hubungan & $\begin{array}{l}\text { Sulit berempati } \\
\text { Tidak memahami untuk } \\
\text { mempertahankan hubungan }\end{array}$ \\
Pengetahuan dasar & $\begin{array}{l}\text { Pangetahuan dasar yang } \\
\text { luas, dalam dan kompleks }\end{array}$ & $\begin{array}{l}\text { Pengetahuan dasar luas, dam, dan terkadang } \\
\text { kompleks }\end{array}$ \\
\hline
\end{tabular}

\section{DAFTAR RUJUKAN}

Coleman, J.Laurence. 1985. Schooling the Giftedness. Canada: AddisonWesley Publishing Company.

Dehaan \& Havighurst. 1962. Educating Gifted Children. USA: the University of Chicago Press.

Gallagher. 1986. Educating Exceptional Children. Boston: Houghton Mifflin Campany.

Hallahan \& Kauffman. 2006. 10th ed. Exceptional Learners: Introduction to Special Education. USA: Pearson Education, Inc.

Hawadi, Reni Akbar. 2005. Identifikasi Keberbakatan Intelektual Melalui Metode Non Tes: dengan Pendekatan Konsep Keberbakatan Renzulli. Jakarta: PT. Gramedia Widiasarana Indonesia.

Hawadi, Wiharjo \& Wiyono. 2001. Kurikulum Berdiferensiasi: Panduan Bagi Penyelenggara Program Percepatan Belajar. Jakarta: PT. Gramedia Widiasarana Indonesia.

Mangunsong, Frieda. 1998. Psikologi dan Pendidikan Anak Luar Biasa. Jakarta: LPSP3 UI.

Munandar, Utami. 1999.
Kreativitas Anak Sekolah: Petunjuk Bagi Para Guru dan Orang tua. Jakarta: PT.Gramedia Widiasarana Indonesia.

Munandar, Utami. 2004. Pengembangan Kreativitas Anak Berbakat. Jakarta: PT.Rineka Cipta.

Parke, Beverly. 1989. Giftedness Students in Regular Classroom. USA: Allyn and Bacon.

Semiawan, Conny. 1997. Perspektif Pendidikan Anak Berbakat. Jakarta: PT.Grasindo.

Winebrenner, Susan. 2001. Teaching Gifted Kids in the Regular Classroom. USA: Free Spirit Publishing.

Mengembangkan Bakat dan 